Professor Ivo Šteiner, MD, PhD, Editor

\title{
CASE 1-2012: ANCA ASSOCIATED GLOMERULONEPHRITIS IN COMBINATION WITH IGG4-POSITIVE MEDIASTINAL MASS IN A PATIENT WITH ANKYLOSING SPONDYLITIS TREATED WITH TNF ALPHA INHIBITORS
}

\author{
Marian Tošovskýl, Petr Bradna ${ }^{1}$, Jan Laco ${ }^{2}$, Miroslav Podhola ${ }^{2}$, Tomáš Soukup ${ }^{1}$, Jan Brožík
}

Charles University in Prague, Faculty of Medicine and University Hospital Hradec Králové, Czech Republic: 2nd Department of Medicine, Department of Rheumatology ${ }^{1}$, The Fingerland Department of Pathology', Department of Radiology ${ }^{3}$

Key words: Ankylosing spondylitis; TNF alpha inhibitors; IgG4-related diseases; ANCA-glomerulonephritis

\section{Introduction}

Ankylosing spondylitis is an inflammatory rheumatic disease affecting predominantly the axial skeleton. The TNF alpha inhibitors have recently led to improvement of the treatment of this disease. In this article we report a case of a patient with ankylosing spondylitis treated with anti-TNF alpha, in whom fever of unknown origin occurred.

\section{Clinical data}

47-year-old man with ankylosing spondylitis was admitted with fever of unknown origin. Diagnosis of ankylosing spondylitis was made 14 years ago based on occurrence of inflammatory back pain, bilateral sacroileitis and HLA B27 positivity. The patient was treated with non-steroidal anti-inflammatory drugs; treatment with TNF alpha inhibitor (adalimumab $40 \mathrm{mg}$ s.c. every other week) had been started ten months before admission. Four months ago the patient started to be subfebrile or febrile $\left(38{ }^{\circ} \mathrm{C}\right.$, sometimes with chills), he suffered from night swelling, fatigue, weight loss ( $5 \mathrm{~kg}$ during the last month) with normal appetite and without changes of bowel movements. The treatment with adalimumab was stopped two months ago. Before admission, several tests and imaging methods were performed, however, the origin of the fever remained unclear (normal chest X-ray, abdominal ultrasonography, scintigraphy of the skeleton, otorhinolaryngologic examination, antinuclear factor and anti dsDNA antibodies as well as quantiferon TB Gold were negative). With persistent fever he was admitted to our Department of Rheumatology.

Laboratory markers of inflammation were elevated (erythrocyte sedimentation rate $101 \mathrm{~mm} /$ hour, CRP $110 \mathrm{mg} / \mathrm{l}$ ), blood count and differential leukocyte count were normal, urine examination showed significant microscopic erythrocyturia $(++++)$ and increasing proteinuria (0.74 g/day...1.2 g/day...2.64 g/day), serum creatinine was initially normal, subsequently the values were increasing $(83 \ldots 113 \ldots 146 \ldots 189 \ldots 212 \mu \mathrm{mol} / \mathrm{l})$. Paraprotein was not detected either in blood or in urine. Infectious aetiology was not found (blood cultures repeatedly negative, as well as other cultures, also Mycobacterium species PCR in serum and urine negative). However, a significant titre of PRO3 ANCA antibodies $(136.8 \mathrm{U} / \mathrm{ml})$ was detected.

High resolution CT (HRCT) of the lung excluded a pneumopathy, but displayed a mediastinal mass in posterior mediastinum $(190 \times 32 \times 53 \mathrm{~mm})$, located perivertebrally, saddle shaped, in contact with dorsal aortic wall. Fluorodexyglucose PET/CT revealed hypermetabolism of this mediastinal mass (Figs. 1-3); another similar mass was found in the aortic arch area $(20 \times 8 \mathrm{~mm}$, Fig. 4), and still another under the bifurcation of abdominal aorta $(30 \times 35 \times$ $10 \mathrm{~mm}$, Fig. 5). A CT-guided biopsy of the mediastinal mass was performed, followed by a kidney biopsy.

\section{Pathological findings}

The mediastinal mass biopsy showed features of an inflammatory pseudotumor with storiform pattern of fibrosis and predominantly lymphoplasmacellular inflammation (Fig. 6). Up to $50 \%$ of plasma cells were IgG4-positive (Fig. 7). Vasculitis was not present. An additional assay of the patient's serum IgG4 level was increased ( $4.7 \mathrm{~g} / \mathrm{l})$.

The kidney biopsy showed presence of acute focal segmental necrotizing pauci-immune glomerulonephritis with cellular crescents in most of the glomeruli (Fig. 8). 


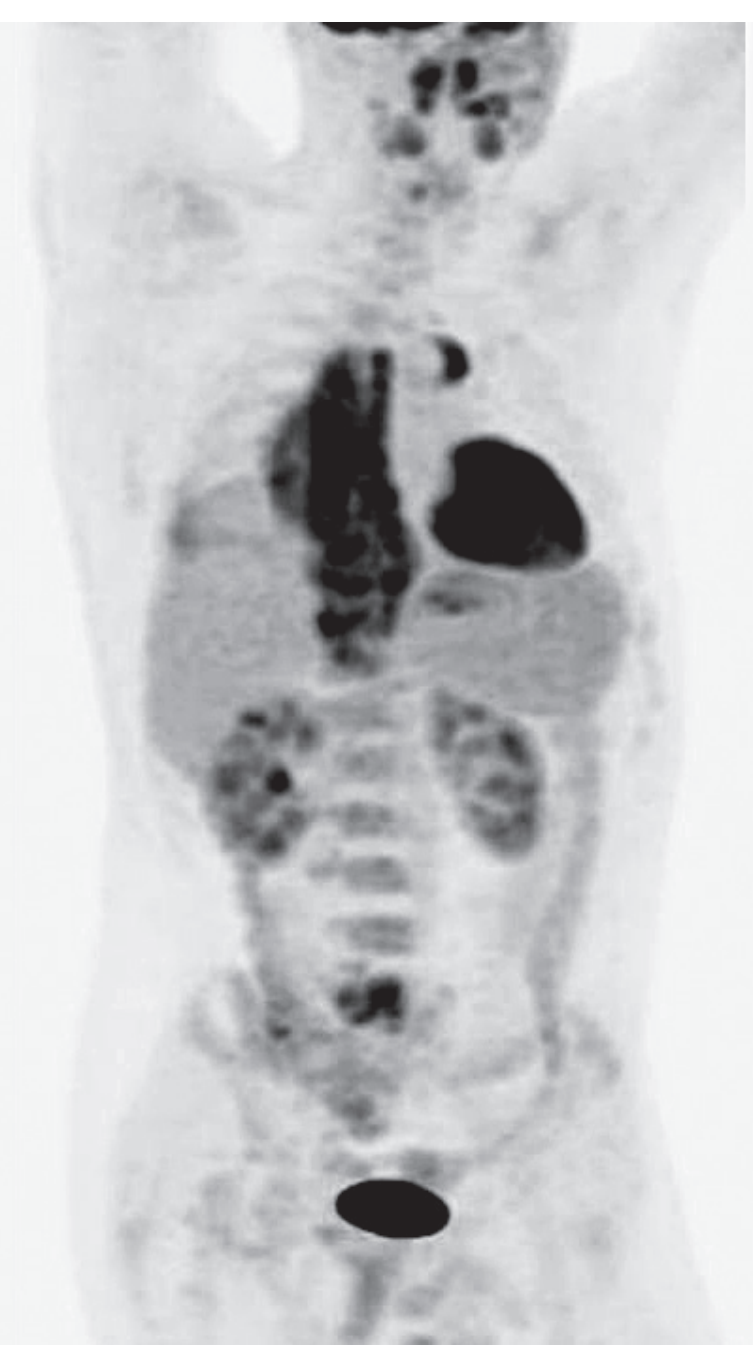

Fig. 1: 3D PET whole body image

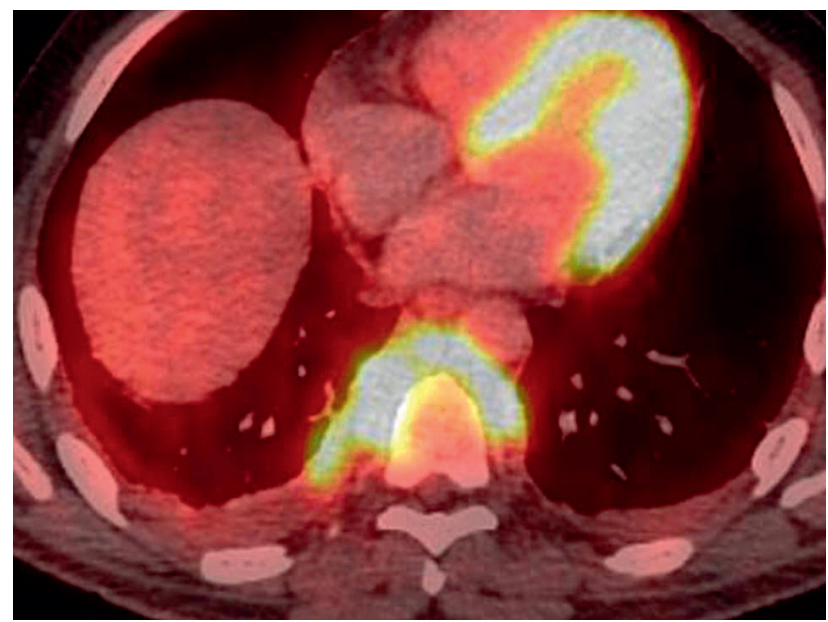

Fig. 2: PET CT fusion tomographic image

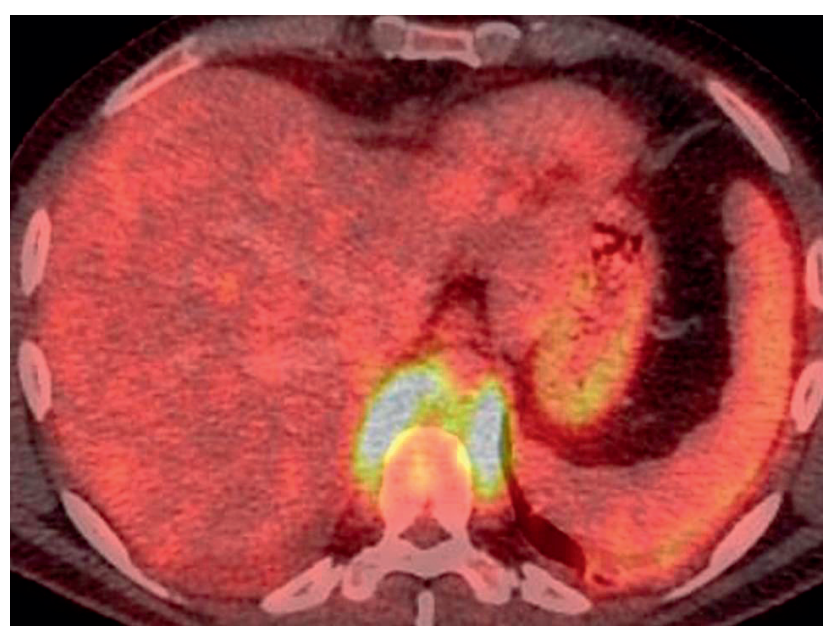

Fig. 3: PET CT fusion tomographic image

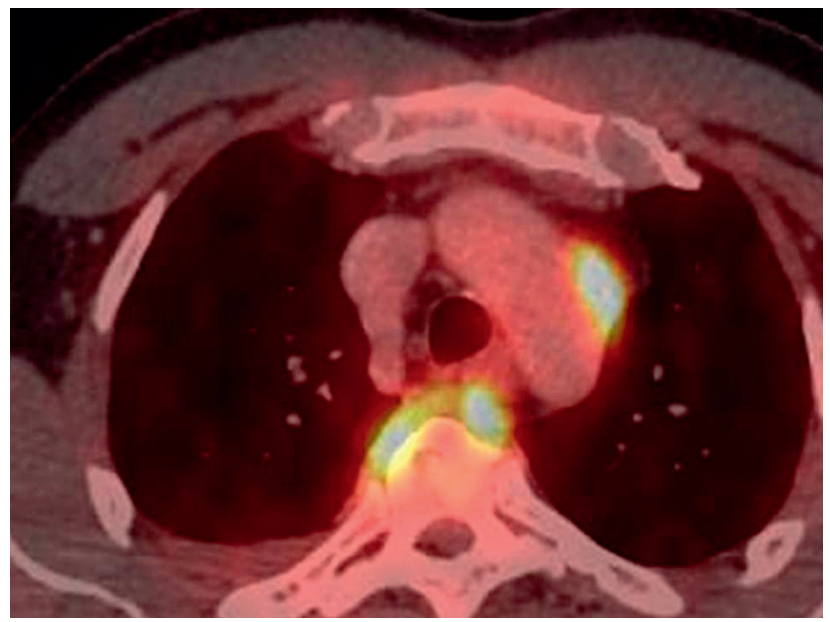

Fig. 4: PET CT fusion tomographic image

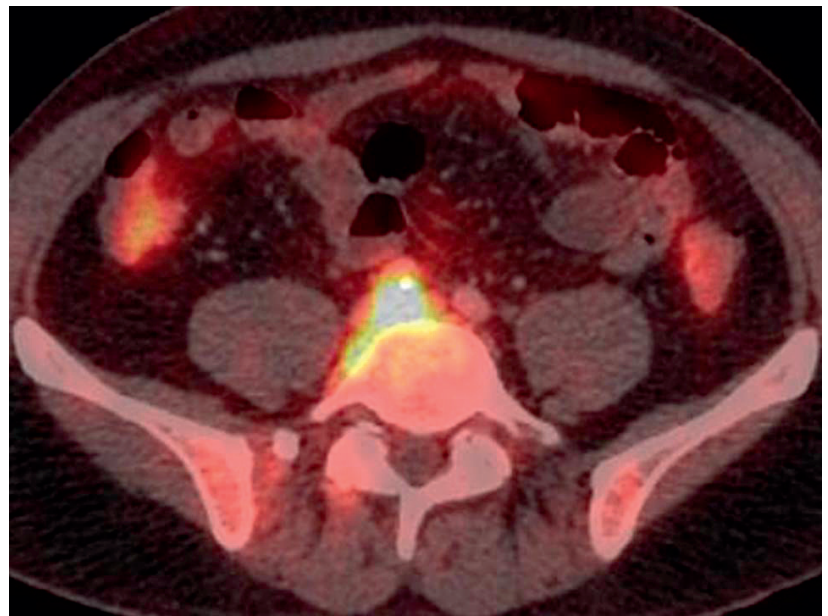

Fig. 5: PET CT fusion tomographic image 


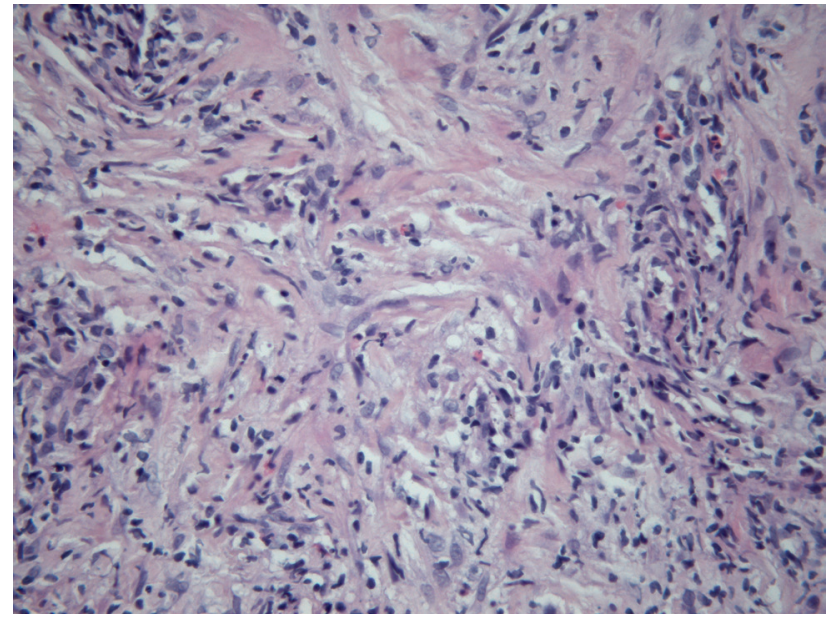

Fig. 6: Storiform pattern of fibrosis and predominantly lymphoplasmacellular inflammation with scattered eosinophils (hematoxylin-eosin, original magnification $400 \times$ )

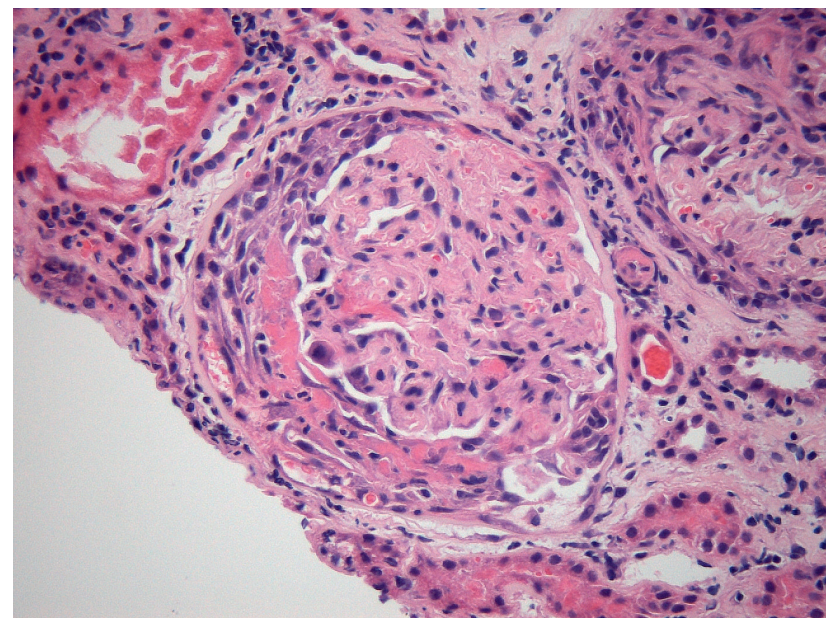

Fig. 8: Cellular crescent in the urinary space with partial collapse of the glomerular tuft (hematoxylin-eosin, original magnification $400 \times$ )

\section{Treatment}

Treatment was started with intravenous pulses of methylprednisolone $5 \times 1 \mathrm{~g}$ every other day and continued with methylprednisolone orally (24 mg daily). Concurrently, treatment with pulses of cyclophosphamide á $1200 \mathrm{mg}$ ( $3 \times$ every 2 weeks, continued every 3 weeks) was started. During the treatment the fever resolved, CRP normalized ( $4.7 \mathrm{mg} / \mathrm{l})$, PRO3 ANCA titres decreased $(9.53 \mathrm{U} / \mathrm{ml})$, proteinuria $(1.22 \mathrm{~g} / \mathrm{den})$, erythrocyturia $(++)$ and creatinine level $(116 \mu \mathrm{mol} / \mathrm{l})$ improved, and the level of IgG4 decreased $(2.5 \mathrm{~g} / 1)$. The mediastinal mass became significantly smaller, with no FDG PET/CT activity (Fig. 9).

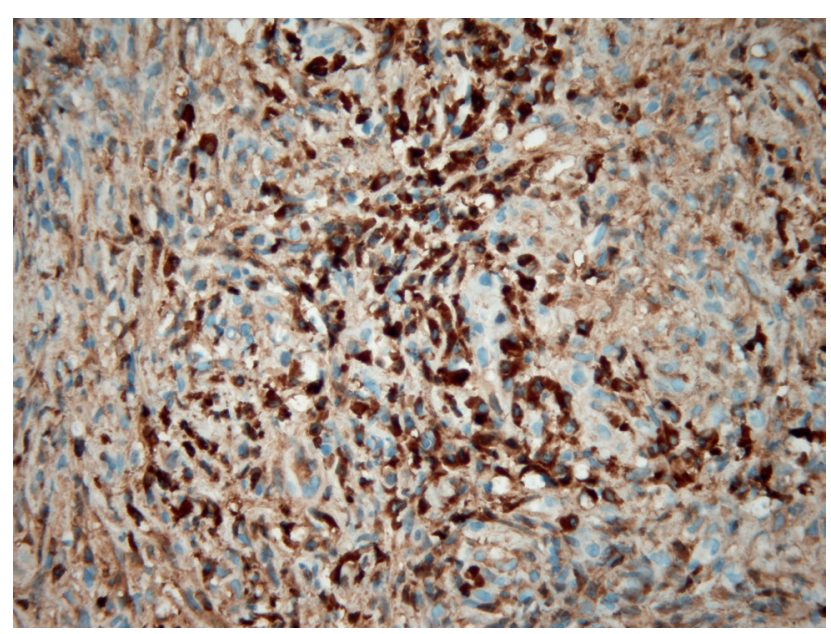

Fig. 7: Numerous IgG4-positive plasma cells in 1 high power field (original magnification $400 \times$ )

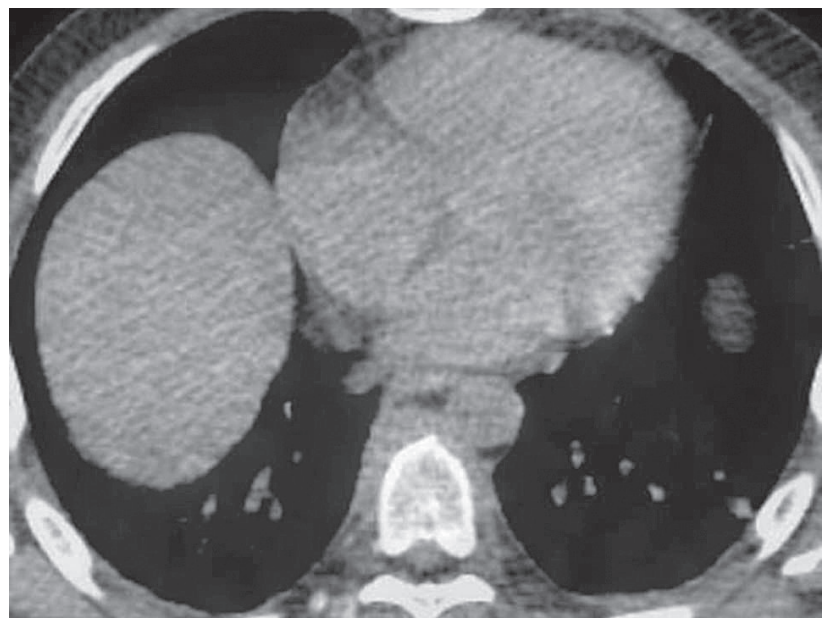

Fig. 9: PET CT fusion tomographic image

\section{Discussion}

Case of a patient with ankylosing spondylitis is reported. The diagnosis of ankylosing spondylitis was established on the basis of presence of bilateral sacroileitis, inflammatory back pain and HLA B27 positivity. Both modified New York criteria for ankylosing spondylitis (14) as well as ASAS criteria for axial spondylarthritis (10) were fulfilled. The patient was treated with anti TNF alpha agent with good effect. During this treatment, there is an increased risk of infection, particularly of tuberculosis (4). Tuberculosis, however, was excluded in our patient.

Two different diseases were diagnosed in our patient concurrently. Both of them may have caused the fever. 
The first one is ANCA-associated glomerulonephritis. The diagnosis was established on the basis of renal biopsy and high titre of PRO3 ANCA antibodies. PRO3 ANCA antibodies are associated with different types of systemic vasculitides. The most frequent one is Wegener's granulomatosis, characterized by granulomatous involvement of upper respiratory tract and lungs. PRO3 ANCA antibodies are detected in approximately $70 \%$ of patients with Wegener's granulomatosis (5). In our patient, however, no granulomata were found in the respiratory system or elsewhere. Likewise, in the mediastinal mass biopsy neither granulomata nor vasculitic changes were present. In the cases of renal-limited involvement, MPO ANCA antibodies are more frequent (64\%), while PRO3 ANCA are less common (20\%) (5). The patient was treated in accordance with EUVAS recommendations (The European Vasculitis Study Group, CYCLOPS study) $(3,8)$.

The second disease detected was an IgG4-positive mediastinal mass. IgG4 is the rarest subtype of human IgG immunoglobulins. An overproduction of IgG4 was found in a number of clinical conditions, generally called IgG4-related diseases. The precise etiopathogenesis of IgG4-related disease remains poorly understood. Microscopic features of IgG4-related disease include various degrees of inflammation, fibrosis and vascular changes (2). There is an increased proportion of IgG4-positive plasma cells. The levels of IgG4 in serum are significantly increased. The common feature of IgG4-related diseases is good response to corticosteroid therapy (6).

The typical manifestation of an IgG4-related disease is autoimmune pancreatitis (15). The other conditions are sclerosing cholangitis, chronic sclerosing sialadenitis (Mikulicz disease), mediastinal and retroperitoneal fibrosis (Ormond's disease), inflammatory pseudotumors of the liver, lung, orbita and others (6). Also large vessel involvement has been recognized as an IgG4-related disease - isolated thoracic aortitis, periaortitis, inflammatory abdominal aortic aneurysm $(7,11)$. The mediastinal mass in our patient was in close contact with thoracic aorta, the small masses were in contact with aortic arch and bifurcation of abdominal aorta, respectively. Renal involvement was also described in patients with IgG4-related disease (tubulointerstitial nephritis or membranous glomerulonephritis), differing however from the involvement found in our patient $(1,12)$.

Anti-TNF alpha treatment is occasionally associated with various autoimmune conditions (most often drug induced systemic lupus erythematodes or vasculitis of skin) (9). Association of ANCA-associated vasculitis with IgG4-related disease has not yet been described.

\section{Conclusion}

We suppose that there were two concurrent diseases in our patient, i.e. ANCA-associated glomerulonephritis, and IgG4-positive mediastinal mass. In the renal biopsy, no changes typical of IgG4-related diseases were found.

\section{Message from the Editor (Prof. Šteiner)}

A 47-year-old man with ankylosing spondylitis (Bechterev's disease) developed fever of unknown origin. During examinations, increased titre of PRO3 ANCA antibodies was detected. High resolution CT displayed a large mass in the posterior mediastinum. Biopsy of the mass showed a pseudotumor with storiform pattern and dense lymphoplasmacytic infiltration with up to $50 \%$ of IgG4-positive plasma cells. The serum level of IgG4 was increased. Renal biopsy showed crescentic (rapidly progressing) glomerulonephritis. Both the renal disease and the mediastinal mass responded well to treatment with methylprednisolon and cyclophosphamide.

The high titre of ANCA antibodies was highly suspicious of vasculitis; this, however, was not confirmed by histology (may be because of only limited size of needle biopsy specimens of the kidney and the mass).

IgG4-related disease is a newly recognized fibroinflammatory condition characterized by tumefactive lesions, a dense lymphoplasmacytic infiltrate rich in IgG4-positive plasma cells, storiform fibrosis, and, often but not always, elevated serum IgG4 concentrations. It has been described in virtually every organ system: pancreas (chronic autoimmune pancreatitis), the biliary tree, salivary glands (Küttner's tumor, Mikulicz's disease), thyroid (Riedel's goiter), periorbital tissues, retroperitoneum (retroperitoneal fibrosis - Ormond's disease), aorta (inflammatory aortic aneurysm), inflammatory pseudotumors, and others. The histopathological features bear striking similarities across organs, regardless of the site of disease (13).

The unique feature of the case presented is simultaneous occurrence of IgG4-related mediastinal pseudotumor and crescentic glomerulonephritis.

\section{Acknowledgements}

This study was supported by research project MZO 00179906 from the Ministry of Health, Czech Republic.

\section{References}

1. Aoki A, Sato K, Itabashi M, et al. A case of Mikuliczes disease complicated with severe interstitial nephritis with IgG4. Clin Exp Nephrol 2009; 13: 367-372.

2. Bateman AC, Deheragoda MG. IgG4-related systemic sclerosing disease - an emerging and under-diagnosed condition. Histopathology 2009; 55: 373-83.

3. de Groot K, Harper L, Jayne DR, et al. Pulse versus daily oral cyclophosphamide for induction of remission in antineutrophil cytoplasmic antibody-associated vasculitis: a randomized trial. Ann Rheum Dis. 2009 May 19; 150(10): 670-80.

4. Gomez-Reino JJ, Carmona L, Valverde VR, Mola EM, Montero MD. Treatment of rheumatoid arthritis with tumor necrosis factor inhibitors may predispose to significant increase in tuberculosis risk: a multicenter active-surveillance report. Arthritis Rheum. 2003; 48(8): 2122-7.

5. Kallenberg CGM, Heeringa P, Stegeman CA. Mechanisms of Disease: pathogenesis and treatment of ANCA-associated vasculitides. Nat Clin Pract Reumatol. 2006; $2: 661-70$.

6. Kamisawa T, Okamoto A. IgG4-related sclerosing disease. World J Gastroenterol 2008; 14: 3948-55

7. Laco J, Steiner I, Holubec T et al. Isolated thoracic aortitis: clinicopathological and immunohistochemical study of 11 cases. Cardiovasc Pathol. 2011 Nov; 20(6): 352-60. Epub 2010 Oct 30.

8. Mukhtyar C, Guillevin L, Cid MC, et al. EULAR recommendations for the management of primary small and medium vessel vasculitis. Ann Rheum Dis. 2009 Mar; 68(3): 310-7. Epub 2008 Apr 15 
9. Pavelka K, Jarošová K. Výskyt autoimunitních onemocnění po aplikaci biologických léků. Čes. Revmatol. 19, 2011; 1: 4-10.

10. Rudwaleit M, van der Heijde D, Landewe R, et al. The development of Assessment of SpondyloArthritis international Society classification criteria for axia spondyloarthritis (part II): validation and final selection. Ann Rheum Dis. 2009; 68: 777-783.

11. Sakata N, Tashiro T, Uesugi N, et al. IgG4-positive plasma cells in inflammatory abdominal aortic aneurysm: the possibility of an aortic manifestation of IgG4-related sclerosing disease. Am J Surg Pathol 2008; 32: 553-9.

\section{Corresponding author:}

12. Shimoyama K, Ogawa N, Sawaki T et al. A case of Mikuliczes disease complicted with interstitial nephritis successfully treated by high-dose corticosteroid. Med Rheumatol 2006; 16: 176-182.

13. Stone, JH, Yoh Zen, MPH, Deshpande, V: IgG4-related disease. N. Engl. J. Med. 2012; 366: 539-551.

14. van der Linden SM, Valkenburg HA, Cats A. Evaluation of diagnostic criteria for ankylosing spondylitis. A proposal for modification of the New York criteria. Arthritis Rheum. 1984; 27: 361-368.

15. Yoshida K, Toki F, Takeuchi T, Watanabe S, Shiratori K, Hayashi N. 491 Chronic pancreatitis caused by an autoimmune abnormality: proposal 492 of the concept of autoimmune pancreatitis. Dig Dis Sci 1995; 40: 493 1561-8.

Marian Tošovský, MD, 2nd Department of Medicine, Department of Rheumatology, University Hospital, Sokolská 581, 50005 Hradec Králové, Czech Republic; e-mail: marian.tosovsky@fnhk.cz 